\title{
DYNAMIC FRICTION AND MICROTURBINE PERFORMANCE USING A PLANAR-CONTACT ENCAPSULATED MICROBALL BEARING
}

\author{
M. Mc Carthy ${ }^{l}$, C. M. Waits ${ }^{2,1}$, and R. Ghodssi ${ }^{1}$ \\ ${ }^{1}$ University of Maryland, College Park, Maryland, USA \\ ${ }^{2}$ U.S. Army Research Laboratory, Adelphi, Maryland, USA
}

\begin{abstract}
Successful demonstration and characterization of a radial inflow microturbine supported on a planar-contact encapsulated microball bearing is presented. Reliable operation of the air-driven silicon microturbine is shown for nearly $1,000,000$ revolutions at speeds, pressure drops, and flow rates of up to $10,000 \mathrm{rpm}, 0.45 \mathrm{psi}$, and $3.5 \mathrm{~s} 1 \mathrm{~m}$, respectively. Incorporation of a gas thrust plenum enables comprehensive spin-down friction characterization of the encapsulated microball bearing. An empirical power-law model for dynamic friction has been developed for speeds and loads of 250$5,000 \mathrm{rpm}$ and $10-50 \mathrm{mN}$, respectively, corresponding to torques of $0.0625-2.5 \mu \mathrm{Nm}$ and friction coefficients of $0.0005-0.025$.
\end{abstract}

\section{INTRODUCTION}

Microball bearings provide a simple, stable, and robust support mechanism for PowerMEMS devices. With inherent tribological and systems-level benefits, microball bearings represent a compromise between the more extensively studied gaslubricated and contact bearings. While gas-lubricated systems have superior speed and friction characteristics [1-2], microball bearing support mechanisms are notably simpler to fabricate and operate. Similarly, microball bearings provide increased tribological performance over sliding contact bearings, where friction and wear substantially impact the operation and life of such devices [3]. Accordingly, our group has demonstrated several microball bearing supported devices exploiting these benefits [4-9]. While microball bearings have been shown to be a reliable and robust support mechanism, the modeling and reduction of friction and wear is necessary for high performance applications.

In our linear and rotary ball bearing-supported variablecapacitance micromotors [4-5], a silicon slider (or rotor) sits on top of steel microballs $(\varnothing=285 \mu \mathrm{m})$ housed in rectangular trenches and is actuated via in-plane electrostatic forces. These electric motors are synchronous machines where the maximum operating speed and force/torque is directly dictated by the bearing friction. Friction increases with speed until the motors cannot generate enough force/torque to maintain synchronization with the moving element, corresponding to maximum linear and rotary speeds of $7 \mathrm{~mm} / \mathrm{s}$ and 500rpm, respectively. Similarly, high-speed microturbines supported on encapsulated microball bearing structures have been demonstrated for speeds up to 37,000 rpm [79]. These devices, however, suffer from excessive wear, leading to particle contamination and geometric deviations. Accordingly, the reduction of friction and wear is critical to the realization of highspeed micromachines like MEMS turbogenerators and electric pumps. The devices and apparatus in this work provide a platform to investigate and mitigate friction and wear in microball bearings.

Characterizing friction in our previous devices was significantly limited by the coupled nature of actuation and normal forces. In the previously published micro- motors and turbines [47], the normal forces were solely dependent on the actuation forces. Using a thrust plenum, these forces have been decoupled in this work allowing for comprehensive spin-down friction testing under a variety of operating conditions relevant to next-generation microball bearing supported PowerMEMS devices.

\section{DEVICE}

To investigate the dependence of speed and normal load on dynamic friction in a MEMS encapsulated ball bearing, microturbines packaged together with a bottom-side thrust plenum have been developed. Figure 1 shows the geometries of the various microturbine components. To minimize friction and wear, the encapsulated microball bearing fabrication process developed by Waits et al. [7-8] was modified to provide planar (Fig. 1a), rather than point, contact between the silicon race and steel microballs. Figure $1 \mathrm{~b} \& 1 \mathrm{c}$ show the radial-inflow microturbine geometry, designed using an incompressible laminar flow velocity triangle method, and a cross-section of the fabricated device. The topside of the device consists of a radial array of inlet orifices and a central outlet where the rotor speed bump structures can be seen (Fig. 1d). Figure 1e shows the underside of the encased rotor which acts as a thrust surface. By pressurizing the backside of the device the rotor is lifted into proper contact with the microballs and spun using pressurized nitrogen passing through the radial-inflow microturbine, as seen in Fig. 2.

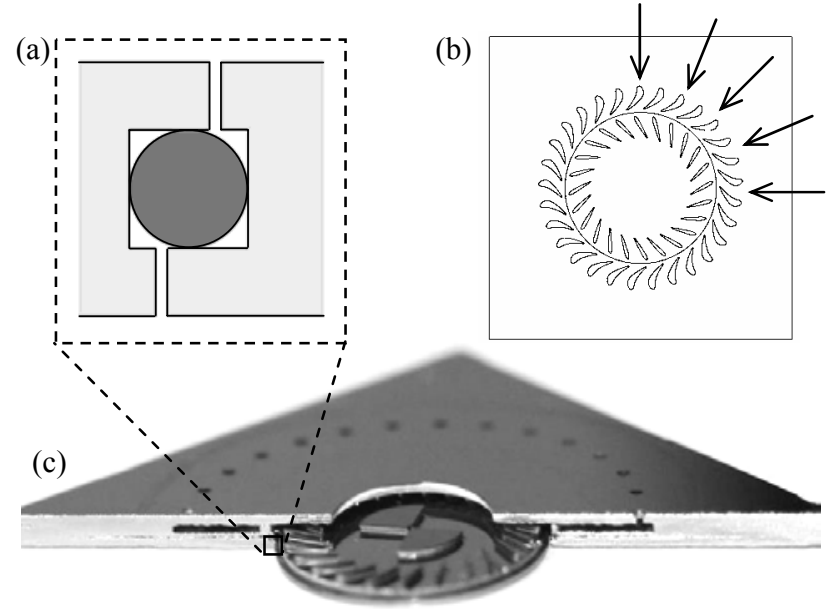

(d)

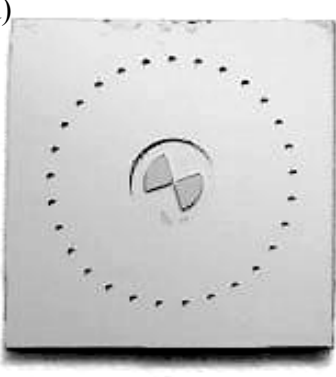

(e)

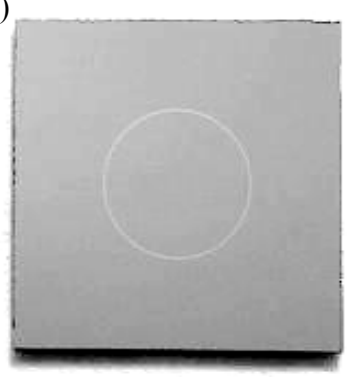

Figure 1: Microturbine device showing (a) the microball bearing geometry $(\varnothing=285 \mu \mathrm{m})$, (b) the blade design and flow direction, and optical photos of (c) the device cross-section with $10 \mathrm{~mm}$ rotor, (d) top side with ports and speed bumps, and (e) the bottom side thrust surface. The total device dimensions are $23 \mathrm{~mm} \times 23 \mathrm{~mm} \times 1.5 \mathrm{~mm}$. 


\section{FABRICATION AND TESTING}

The microturbine fabrication process consists of wafer-level construction of encapsulated rotors followed by die-level temporary bonding of a capping layer to create internal flow paths. The microball housing is defined with a nested deep reactive ion etch (DRIE) in a pair of silicon wafers and approximately ninety stainless steel microballs are encased between the wafers using a gold/tin eutectic bond. The wafer stack is diced and individual die are deep-etched using patterned $\mathrm{SiO}_{2}$ masks to define turbine structures and release the rotors, this is followed by photoresist bonding of a capping layer containing fluid inlet and outlet ports.

Complete characterization of dynamic friction in the planarcontact encapsulated microball bearing requires independent control of rotor speed and normal load. These parameters are decoupled through the use of a hydrostatic thrust plenum defined by a novel packaging assembly. Figure 2 shows schematics of the device cross-section and operation while Figure 3 is an optical photo of a packaged device being tested, showing fluidic ports and the optical probe used to track rotor speed. Complete details of the device fabrication and testing apparatus have been reported previously at PowerMEMS '07 [9].

(a)

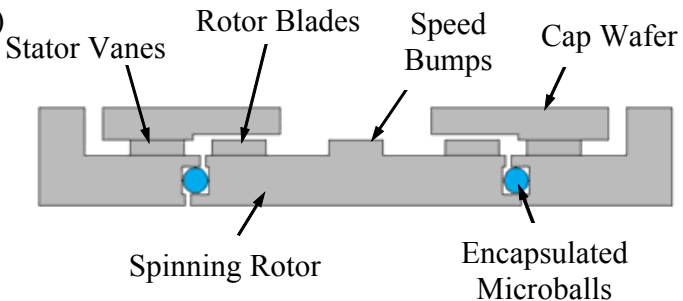

(b)

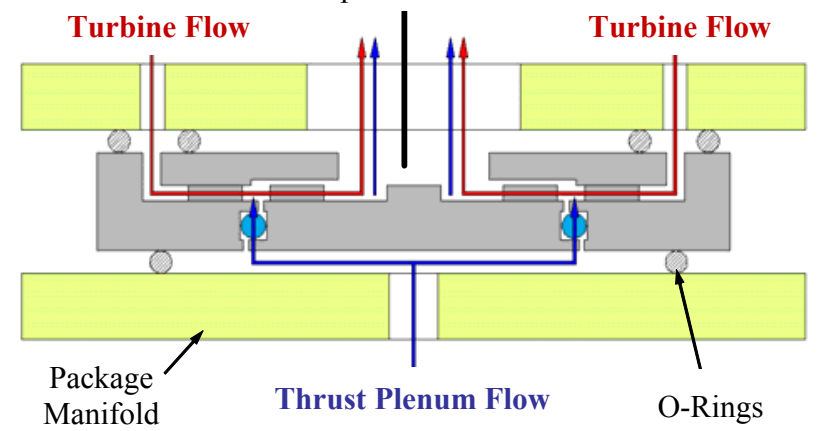

Figure 2: Schematic showing (a) the microturbine cross-section and (b) the experimental operation of the device indicating flow paths for the turbine and thrust plenum.

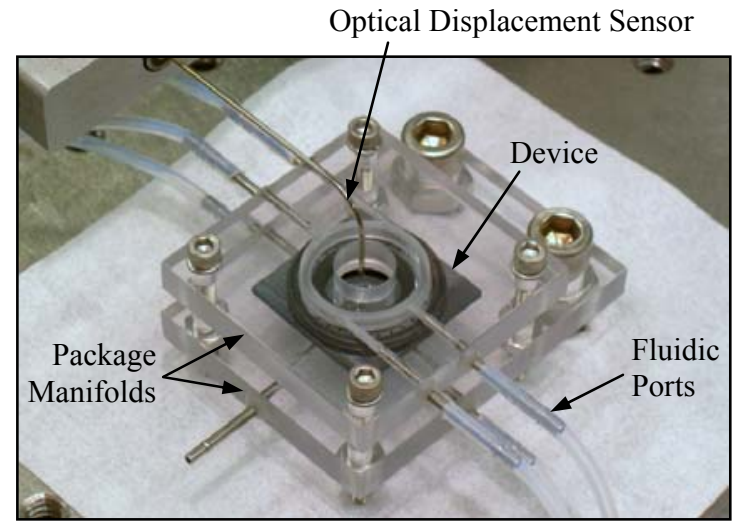

Figure 3: Photo of a packaged microturbine being tested.

\section{RESULTS AND DISCUSSION}

Microturbine Characterization

Using the packaging scheme shown in Figs. 2-3, the microturbine has been characterized up to $10,000 \mathrm{rpm}$. As turbine flow passes over the rotor periphery (Fig. 2b), the underside is pressurized resulting in a net upward normal force without the addition of thrust plenum flow. While this novel packaging approach decouples normal and rotational forces during spin-down testing, the two are very much coupled during turbine actuation. Rotational speed, normal force, and flow rate are plotted in Figure 4 as a function of turbine inlet pressure, in the absence of thrust plenum flow. Figure 4a shows alternate paths for increasing and decreasing actuation at low speeds; this can be attributed to a variety of factors. First and foremost, this is a likely product of higher static friction than dynamic. Other possible contributors are net radial forces and a varying slide-to-roll ratio of the microballs during start-up. Figure $4 \mathrm{~b}$ shows a linear relationship between inlet pressure and rotor normal force, demonstrating the coupled nature of normal and rotational forces during actuation.
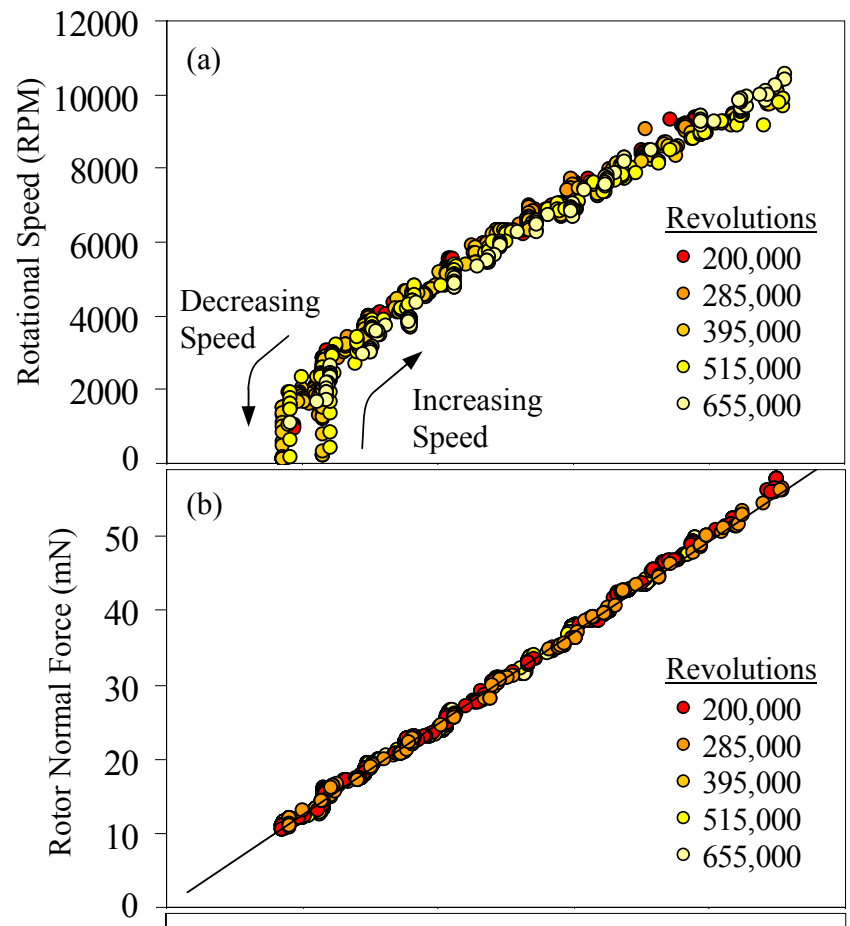

(c)

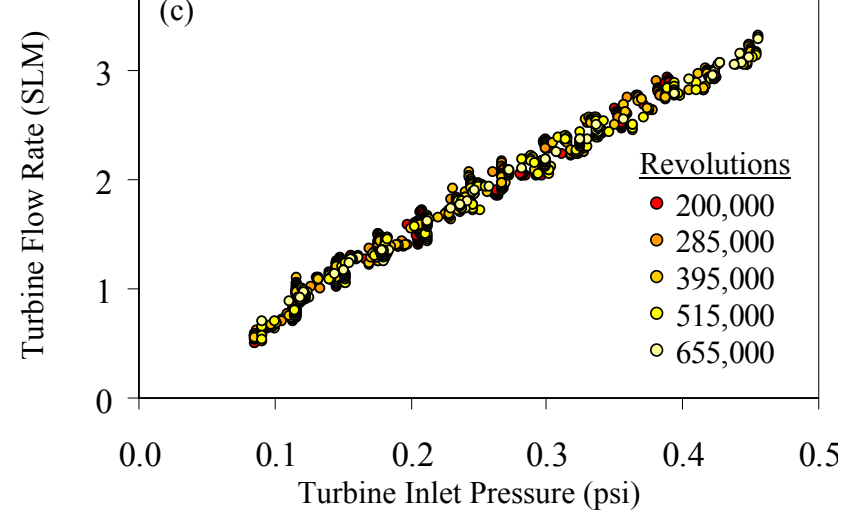

Figure 4: Turbine operating curves for (a) rotational speed, (b) rotor normal force, and (c) turbine flow rate as a function of turbine inlet pressure, with no thrust plenum flow. 


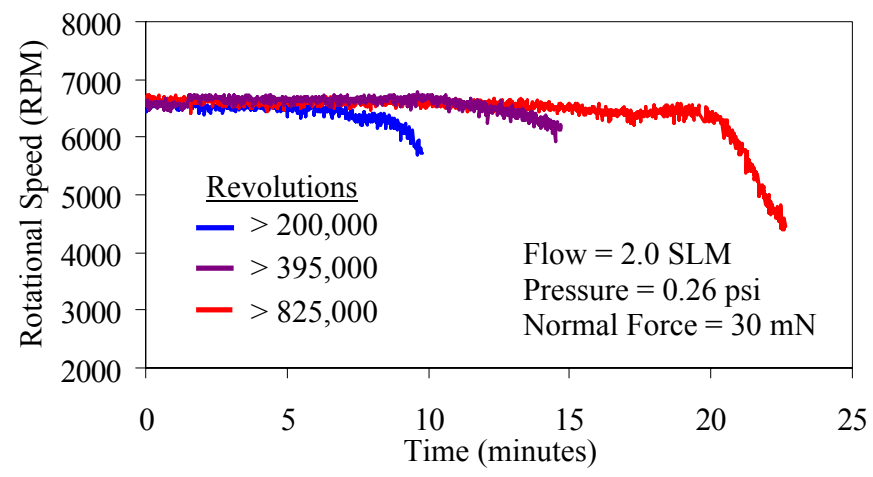

Figure 5: The effect of wear debris on turbine performance after prolonged operation. After each data set the device is cleaned and returns to the expected behavior.

\section{Effect of Wear Debris}

After continuous operation, wear debris builds up slowing the turbine due to increased friction. Accordingly, the device is cleaned periodically in an ultrasonic bath to remove wear particles. After cleaning, the turbine performance returns to the expected behavior, showing longer operation with increased revolutions, as seen in Fig. 5. Each data set of the characterization curves (Fig. 4ac) was collected after ultrasonic cleaning. This shows that while wear debris limits the duration of the device, wear itself (geometric deviation from the as-fabricated state) has virtually no effect on performance, for the loading conditions considered.

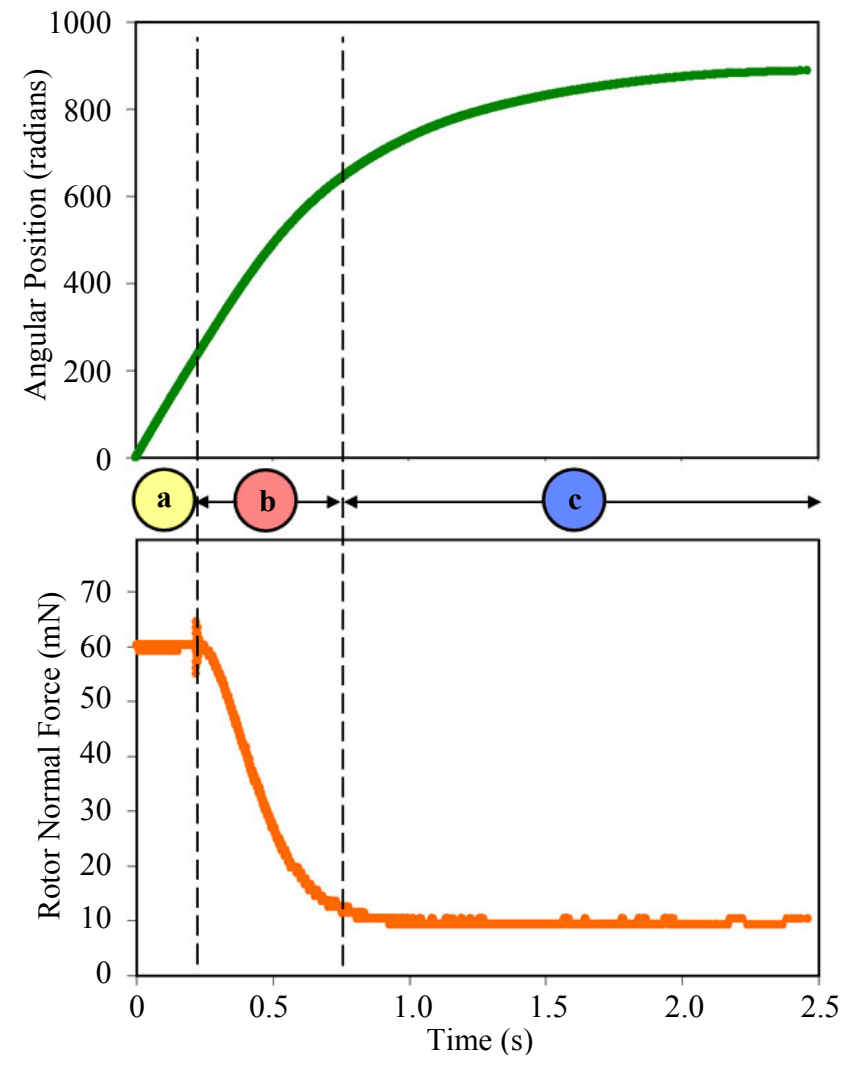

Figure 6: Spin-down data acquisition procedure. (a) The turbine is spun at a constant speed of 10,000rpm. (b) The turbine flow is shut off and the speed and normal force decrease. (c) The normal force equilibrates to the pre-set value $(10 \mathrm{mN})$. Spin-down data is acquired during this stage as the rotor decelerates under a specified constant normal force.

\section{Spin-Down Friction Testing}

Comprehensive characterization of dynamic bearing friction is achieved through spin-down testing using the backside thrust plenum (Fig. 2b) to achieve a desired normal rotor force. The spindown response of the microturbine (Fig. 6) can be separated into three distinct stages. Initially, the turbine is spinning at a constant speed $(\sim 10,000 \mathrm{rpm})$ corresponding to a linear increase in angular position and an elevated constant thrust force (stage a). The turbine flow is shut off and the thrust force decreases dramatically as the rotor begins to slow down (stage b). Finally, stage c corresponds to the period after the thrust load equilibrates to within $10 \%$ of the pre-set desired value $(10 \mathrm{mN}$ in this case). Spin-down data is acquired during stage c. An optical probe measures angular position, $\theta$, as the rotor decelerates under a prescribed constant normal force provided by the thrust plenum.

To characterize the effects of speed and load on dynamic bearing friction, this testing procedure is repeated for several normal loads. Figure 7 shows spin-down data acquired at several thrust forces, showing faster spin-down at higher loads, as would be expected. These position versus time data sets fit well to an exponential function of the form

$$
\theta=A\left(1-e^{-B t}\right)
$$

(with coefficients A \& B). The result is a linear relationship between angular acceleration $(\ddot{\theta})$ and angular velocity $(\dot{\theta})$,

$$
\ddot{\theta}=-B \dot{\theta},
$$

and therefore a linear relationship between friction torque, calculated as the product of the angular acceleration and rotor mass moment of inertia $\left(\tau_{\mathrm{F}}=\mathrm{I} \ddot{\theta}\right)$, and bearing speed $(\omega=\dot{\theta})$. Accordingly, each spin-down at a constant normal force $\left(\mathrm{F}_{\mathrm{N}}\right)$ corresponds to a single ratio of friction torque to bearing speed

$$
\frac{\tau_{F}}{\omega}=|I \cdot B|=f\left(F_{N}\right)
$$

where $I$ is the rotor mass moment of inertia and $B$ is the coefficient determined from numerical fitting.

This testing and data reduction scheme is repeated sequentially at various intervals up to 825,000 revolutions for normal loads from $10-50 \mathrm{mN}$. These loads correspond to the range of expected values in next-generation electrostatic and magnetic micromotors and microgenerators being developed by our group.

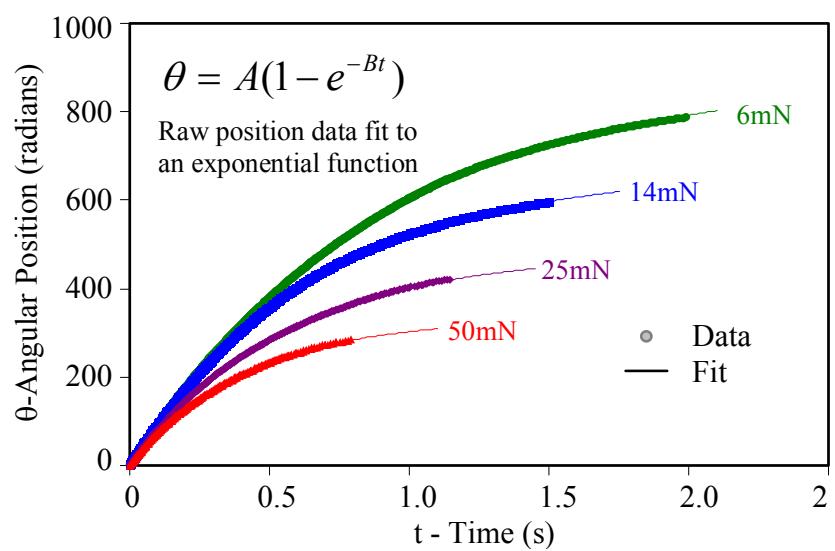

Figure 7: Spin-down trajectory data for several normal loadings fit to an exponential function with constants $A \& B$, resulting in a linear relationship between deceleration and speed. 
The dependence of the ratio of friction torque to bearing speed $\left(\tau_{\mathrm{F}} / \omega\right)$ on the normal load $\left(\mathrm{F}_{\mathrm{N}}\right)$ is plotted in Figure 8 for intervals up to 825,000 revolutions. Accordingly, an empirical power-law model for friction torque of the form $\tau_{\mathrm{F}}=\mathrm{CF}_{\mathrm{N}}{ }^{\mathrm{D}} \omega$ has been developed for speeds and loads of 250-5,000rpm and 10$50 \mathrm{mN}$, respectively, corresponding to $0.0625-2.5 \mu \mathrm{Nm}$ of friction torque. This results in coefficients of dynamic rolling friction varying from 0.0005 (at $250 \mathrm{rpm}$ and $50 \mathrm{mN}$ ) to 0.025 (at $5,000 \mathrm{rpm}$ and $10 \mathrm{mN}$ ). Figure 9 shows the evolution of the modeling constants (C\&D) at every interval. After an initial period of 'runin', repeatable results from 100,000 to 825,000 revolutions are observed corresponding to the developed model shown in Fig 8.

The test device and experimental apparatus presented in this work provide a platform to characterize and optimize friction and wear in encapsulated microball bearing support mechanisms. This is the first demonstration of such a system, independently investigating the effects of speed and load. Using this platform complete characterization of bearing friction over a range of relevant operating conditions has been achieved. Additionally, the onset and effects of wear have been identified. Continued work will focus on the incorporation of thin-film hard-coatings into the bearing housings to mitigate the effects of friction and wear.

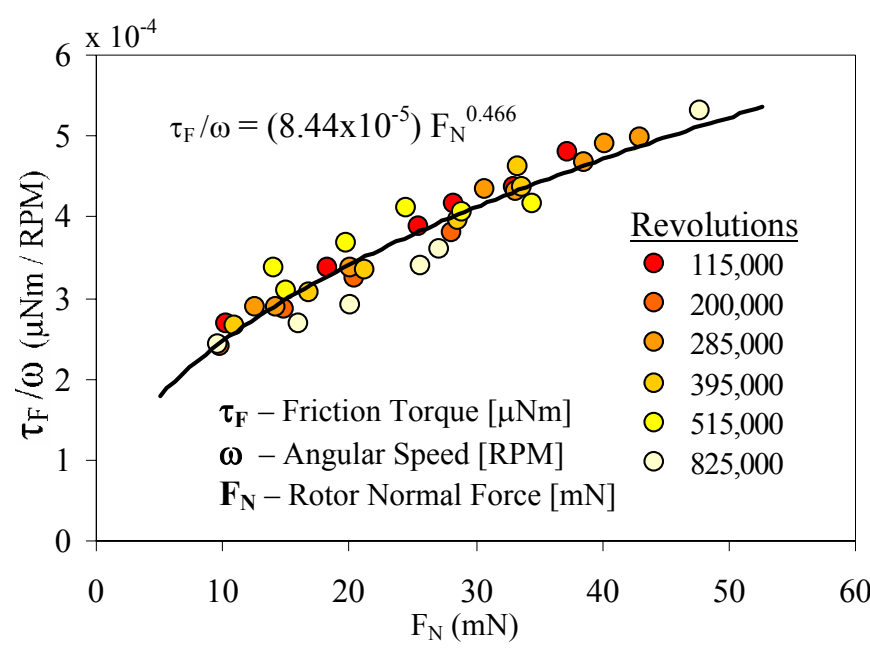

Figure 8: Linear proportionality between friction torque and speed as a function of rotor normal force at various intervals, showing good agreement with a power-law relation up to 825,000 revolutions.

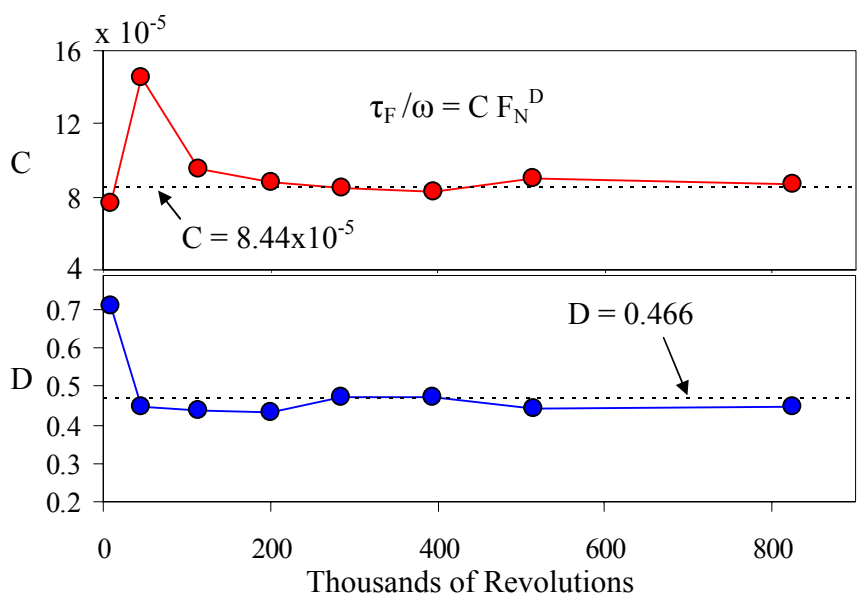

Figure 9: Empirical modeling constants from spin-down friction tests, equilibrating after an initial period of wear.

\section{CONCLUSIONS}

Reliable and stable operation of a silicon microturbine supported on a planar-contact encapsulated microball bearing has been demonstrated. A novel testing apparatus has enabled the first characterization and empirical modeling of dynamic friction in microball bearings over operating conditions relevant to the development of a wide range of rotary micromachines. This apparatus has provided quantitative and qualitative information on the nature and prominence of friction and wear in such bearing systems. Additionally, this platform will allow the investigation and optimization of these critical bearing parameters through the use of hard-film coatings. The technologies presented here will act as robust drive and support mechanisms for the high-speed rotary micro- generators, motors, electric-pumps and turbopumps currently in development by our group.

\section{ACKNOWLEDGMENTS}

This work was supported by the U.S. Army Research Laboratory under Grant No. CA\#W911NF-05-2-0026.

\section{REFERENCES}

[1] L. Fréchette, S. Jacobson, K. Breuer, F. Ehrlich, R. Ghodssi, R. Khanna, C. Wong, X. Zhang, M. Schmidt, and A. Epstein, "High-Speed Microfabricated Silicon Turbomachinery and Fluid Film Bearings", Journal of Microelectromechanical Systems, 14, 1, pp.141-152 (2005).

[2] C. Livermore, A. Forte, T. Lyszczarz, S. Umans, A. Ayon, and J. Lang, "A high-power MEMS electric induction motor," Journal of Microelectromechanical Systems, 13, pp.465-471 (2004).

[3] M. Mehregany, S. D. Senturia, and J. H. Lang, "Measurement of wear in polysilicon micromotors," IEEE Transactions on Electron Devices, 39, pp.1136 (1992).

[4] N. Ghalichechian, A. Modafe, J. H. Lang, and R. Ghodssi, "Dynamic Characterization of a Linear Electrostatic Micromotor Supported on Microball Bearings," Sensors and Actuators: A. Physical, 136, 2, pp.416-503, (2007).

[5] N. Ghalichechian, A. Modafe, M. Beyaz, and R. Ghodssi, "Design, Fabrication, and Characterization of a Rotary Micromotor Supported on Microball Bearings," Journal of Microelectromechanical Systems, In Press, December 2007.

[6] N. Ghalichechian, M. McCarthy, M. Beyaz, and R. Ghodssi, "Measurement and Modeling of Friction in Linear and Rotary Micromotors Supported on Microball Bearings," Technical Digest of the IEEE International Conference on Microelectromechanical Systems (MEMS), Tucson, AZ, USA, January 13-17, 2008.

[7] C. M. Waits, N. Jankowski, B. Geil, and R. Ghodssi, "MEMS Rotary Actuator using an Integrated Ball Bearing and Air Turbine", Technical Digest of the International Conference on Solid-State Sensors and Microsystems (Transducers), Lyon, France, June 10-14, 2007.

[8] C. M. Waits, B. Geil, and R. Ghodssi, "Encapsulated Ball Bearings for Rotary Micromachines," Journal of Micromechanics and Microengineering, 17, pp. S224-S229 (2007).

[9] M. McCarthy, C. M. Waits, and R. Ghodssi, "Development of a Hybrid Gas/Ball Bearing Support Mechanism for Microturbomachinery," International Workshop on Micro and Nanotechnology for Power Generation and Energy Conversion Applications (PowerMEMS), Freiburg, Germany, Nov. 28-29, 2007. 